Tavassoli E Sune (2018)

Volume 3 Issue 3, pp.1616-1636

Date of Publication: 20th February 2018

DOI-https://dx.doi.org/10.20319/pijss.2018.33.16161636

This paper can be cited as: Tavassoli, T., E Sune, A. (2018). A National Study on the Antecedents and Outcomes of Work-Life Balance in Iran. PEOPLE: International Journal of Social Sciences, 3(3) pp

\title{
A NATIONAL STUDY ON THE ANTECEDENTS AND OUTCOMES OF WORK-LIFE BALANCE IN IRAN
}

\author{
Tara Tavassoli* \\ Universitat Politecnica de Catalunya, Department of Management, Barcelona, Spain \\ tara.tavassoli@estudiant.upc.edu
}

\begin{abstract}
Albert Sune
Universitat Politecnica de Catalunya, Department of Management, Terrassa, Spain albert.sune@upc.edu
\end{abstract}

\begin{abstract}
This paper examines the impact of work-life balance (WLB) on individual outcomes of full time employees in Iran. This research aims to identify the influence of WLB on job satisfaction, life satisfaction, and turnover intentions. Moreover, this paper aims to identify the influence of a selected group of antecedents (job autonomy, work demands and supervisor work-family support) on WLB. Structural equation modeling in AMOS is used to analyze data from a sample of 203 full time workers in Iran. Analysis of data reveals positive relationships between WLB and job and life satisfaction while negative relationships between WLB and turnover intentions. The results also show significant relationships with all the studied antecedents of WLB. Job autonomy and supervisor work-family support have a positive relationship with WLB while work demands have a negative relationship with WLB. This is one of the first studies to analyze antecedents and outcomes of WLB in Iran. The results show that WLB is a relevant factor in the Iranian society. Employees that are able to balance all their life roles experience higher satisfaction and have less intention to leave their organization. In addition, the perception of balance is strongly influenced by work and family conditions. These findings align with other


national studies in Western countries. Further research is needed to assess other work and nonwork conditions that might influence $W L B$, for example, the role that colleagues, supervisors and HR management play in creating supportive work environments. It would also be valuable to extend the current study to other countries to develop a comparative cross-national research.

\section{Keywords}

Work-Life Balance, Life satisfaction, Work satisfaction, Turnover intentions, Supervisor support.

\section{Introduction}

Recent studies have considered Work-life balance (WLB) a relevant topic in the worklife research field (Greenhaus \& Allen, 2011; Haar, Russo, Sune, \& Ollier-Malaterre, 2014). Achieving balance between work and life domains is a challenge that full time employees face. Despite its generality, there is still little research on the causes and effects of WLB (Kossek, Valcour, \& Lirio, 2014). Most of the previous work in the work-life research field has focused on work-family conflict (Allen, Herst, Bruck, \& Sutton, 2000). However, in this study, we aim to build on the concept of WLB as people's assessment of balance between their job and personal life (Greenhaus \& Allen, 2011; Haar et al., 2014). Kalliath and Brough (2008) defined work-life balance based on the employees' understanding of balance between work and non-work roles. Allen et al. (2000) identified several effects of work-life balance, for example work-related outcomes like increased job satisfaction, reduced turnover intentions, reduced absenteeism and higher performance; and non-work-related outcomes like marital, family and life satisfaction. This research aims to study the antecedents and outcomes of WLB in Iran. We chose Iran because work-life issues in Middle East cultures are still understudied (Lagerström et al., 2010). Our literature review reveals that most studies on WLB have been carried out in the Western countries and, in particular, in USA. Thus, studying this topic in Middle East countries like Iran would be a research opportunity (Karimi, 2006). In Iranian culture, an individual's personality is related to the identity of the family (O'Shea, 2003). Fu and Shaffer (2001) revealed that regardless of the fact that Iranian women are now more educated, take part in the workforce, and have the same employment opportunities as men, they still hold primary responsibility for family 
duties. Traditional roles between men and women are still dominant in Iranian culture nowadays. In the past, men were considered the family members to provide livelihood while women were committed to family responsibilities such as caregiving, cooking, and housekeeping. However, some social and economic changes are occurring in Iran recently, moving towards Western societies (Karimi, 2008). For instance, in the last decade, female participation in the workplace increased to 22\% (Schwab, 2016). Economic changes such as globalization and growth of the global market are also playing out (Karimi \& Nouri, 2009). In addition, the traditional family roles are slowly starting to change. For instance, men are becoming more involved in household duties (O’Shea, 2003). There is a larger number of female doctors, academic, athletes, and other professional jobs (O'Shea, 2003; Karimi, 2006). As a consequence, the traditional family is being replaced by a dual-career family (Karimi, 2009). Iran is facing a transitional period from traditional to modern (Karimi \& Nouri, 2009; Beigi et al., 2012), while traditional rules are still dominant (Beigi et al., 2012). In such an evolving culture, we expect interesting results regarding the antecedents and effects of WLB.

\section{Literature Review}

Work-life balance is considered a measure of the quality of life which is assessed by the OECD life index (OECD, 2017). WLB describes how much an employee feels balance between work and non-work roles (Guest, 2002; Haar et al., 2014). WLB was firstly defined as satisfaction and a sense of harmony between different aspects of life like work, play and love (Kofodimos, 1993). Few years later, Greenhaus and Powell (2003) defined WLB as the degree to which a person is involved in his or her work and non-work activities and described three types of balance: time balance (same time between job and personal life), involvement balance (same psychological participation in job and life) and satisfaction balance (equal satisfaction between job and personal life). This definition is based on the individual's perception which contributes to individual's' perspective, preferences, targets and attitudes (Kossek et al., 2014). Occurring changes in families and workplaces like dual-earner families and employed women with young children may increase the probability of having significant household responsibilities besides work duties and experience distress (Bond, Galinsky, \& Swanberg, 1997; Nishaat, 2017). To 
cope with these changes, some organizations started to apply new family support programs and policies (Lobel \& Kossek, 1996). These policies include flexible work hours, leaves or absence periods, etc. Although applying these policies may help employees to manage multiple job and family demands, perceptions of balance may not enhance accordingly (Allen, 2001). As a consequence more studies are needed to investigate the antecedents and outcomes of WLB in different cultural contexts.

\subsection{Work-Life Balance and Its Outcomes}

\subsubsection{Job satisfaction}

The expected main effects of WLB are better health conditions and higher performance in work and non-work activities (Brough et al., 2014). Greenhaus et al. (2003) found that employees who experience balance are mentally healthier since they are able to create a sense of harmony in all their life roles. Wise and Bond (2003) found that the benefits of WLB include improved recruitment, retention, and job quality. We expect that Iranian employees who enjoy higher levels of WLB would experience higher levels of job satisfaction (Greenhaus et al., 2003) and that would help them to achieve progress in their careers. Thus we hypothesize that:

\section{H1: WLB is positively related to job satisfaction in Iran.}

\subsubsection{Life satisfaction}

Marks and MacDermid (1996) suggested that role balance is the intention to fulfill all roles with an attitude of attentiveness. Kirchmeyer, (2000) reported that balance means that work and other life roles receive similar levels of attention, devotion, and commitment. Clark (2000) found that work-family balance is related to high performance at both job and life with the lowest level of conflict between job and home roles. Some studies found that work-family balance increased employees' satisfaction at both family and work domains (Clark, 2000; Kirchmeyer, 2000). WLB may also increase satisfaction with family roles (Greenhaus, Collins, \& Shaw, 2003). Thus, we expect that WLB is likely to increase life satisfaction of Iranian employees:

H2: WLB is positively related to life satisfaction in Iran. 


\subsubsection{Turnover intentions}

Lack of WLB may influence turnover intentions because employees may find difficulties to equally enjoy all life roles. In some cases finding a new job might be perceived as an option to better balance work and non-work activities (Noor \& Maad, 2009). WLB practices were found critical for firms aiming to minimize their employees' turnover (Soon et al., 2005). Thus, we expect that Work-life balance may reduce turnover intentions among employees (Casper \& Harris 2008). Accordingly we hypothesize that:

H3: $W L B$ is negatively related to turnover intentions in Iran.

\subsection{Antecedents of WLB}

\subsubsection{Job Autonomy}

Job autonomy has been defined as the degree of employees' independence, freedom and ability to self-organize work (Hackman \& Oldham 1975, Ahuja, et al. 2007). Job autonomy is likely to influence employees' attitude towards their freedom to start, organize and fulfill work tasks (Kaldenberg \& Becker, 1992; Xie \& Johns, 1995). Thomas and Ganster (1995) found that higher autonomy at the workplace was associated to lower work-family conflict. Other scholars suggested that job autonomy would be beneficial to help employees to better manage their available resources according to job and family demands (Beauregard \& Henry 2009). Autonomy provides employees freedom and flexibility to manage their workloads. Thus higher autonomy might be associated to higher WLB. Therefore, we hypothesize that:

H4: Job autonomy is positively related to WLB in Iran.

\subsubsection{Work Demands}

Work demands have been defined as additional pressure due to high volume of work and working time such as deadlines (Yang et al. 2000; Boyar et al. 2003). Previous studies found that work demands like daily work hours, work pressure, and night shifts were negatively associated to balance (Burke, 2002; Voydanoff, 1988; Yildirim \& Aycan, 2008). Byron (2005) found that the relationships between work demands and work-family conflict are significant. O'Driscoll, Brough and Biggs (2007) and Brough, O'Driscol, and Kalliath (2007) also investigated the influence of work demands on work-family conflict with similar results. From the balance perspective, working night shifts, weekends or long hours may reduce the time that 
would be devoted to non-work activities. Thus, we expect that higher work demands, like working time, workload, or irregular work schedules are likely to be associated to lower WLB (Yildirim \& Aycan, 2008; Steiber, 2009). Accordingly, we state that:

H5: Work demands are negatively related to WLB in Iran.

\subsubsection{Supervisor Work-Family Support}

Giving and receiving social support from close relations may increase life satisfaction (Sultan, Kanwal, \& Gul, 2017). A family-supportive supervisor assists employees to accommodate their family responsibilities (Thompson, Beauvais, \& Lyness, 1999). Supervisors may collaborate with their staff to balance job and life roles by allowing them to organize their work time and resources or allowing them to leave the workplace in case of personal emergency events (Wang et al., 2008). Supervisor work-family support could be psychological, for instance showing care and concern to employees' family issues (Wadsworth \& Owen, 2007; Ferguson et al., 2012). Therefore the employees' skills and trust might be increased and this may prevent tensions and strains. However, work and life have been traditionally considered separate domains in Iran, and supervisors did not consider employees' life responsibilities as relevant to their work. Given this general lack of support from supervisors in Iran, when it occurs, it might be perceived as something valuable by employees. As a consequence, supervisor support may increase WLB in Iran. Accordingly we expect that:

H6: Supervisor work family support is positively related to WLB in Iran.

Figure 1 illustrates the hypotheses stated above as relationships among the studied factors. 


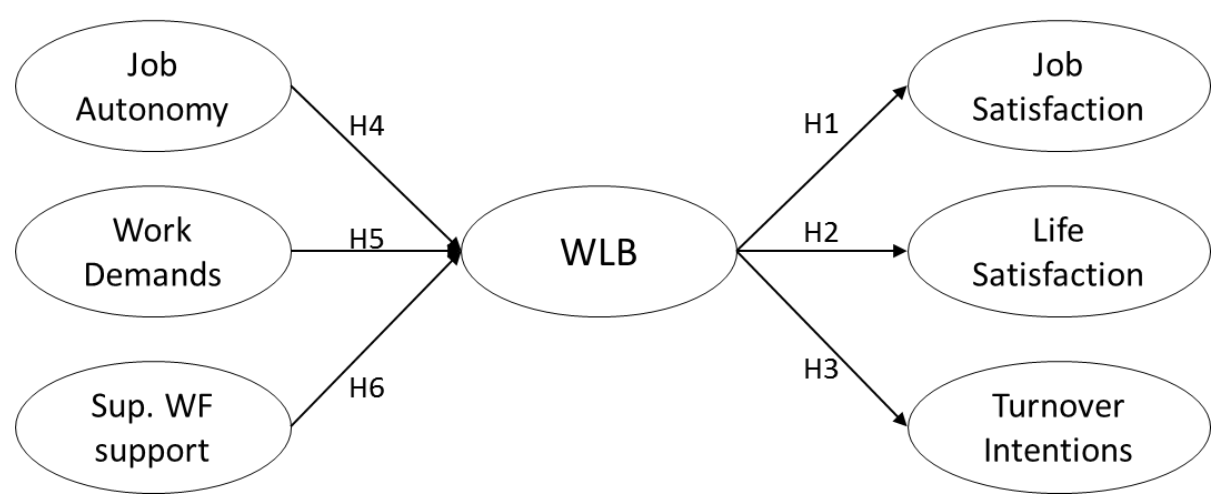

Figure 1: Hypothesized model

\section{Methods}

\subsection{Samples and Procedures}

As mentioned above, we choose Iran since we found that there is still little research on WLB in this country as most studies in this field have been developed in Western countries and mostly in the USA (Karimi, 2009) and the Iranian society is evolving from traditional to modern family roles. To fill this gap we developed an empirical study and we asked full-time Iranian employees about several factors related to work and life issues. It was necessary that participants were involved in a full-time job. We used questionnaires as they are the most prevalent method of obtaining data in management research (Moorman \& Podsakoff, 1992). Questionnaires have some advantages; they are convenient to use, inexpensive, and they are a common method for measuring unobservable variables such as attitudes, ideas, and personalities (Moorman and Podsakoff, 1992). Since all the scale items were originally created in English, the questionnaire was translated into the Persian language for Iranian employees. Most of the questionnaires were distributed to the participants personally but in few cases we sent them by email. We asked 203 employees to participate in this study and we finally received 136 completed questionnaires. The responses rate was $66 \%$. The average age was 39.7 years. The sample gender was $25 \%$ female and $75 \%$ male. We used a 5-point Likert scale that ranges from 1-strongly disagree to 5-strongly agree in all the questionnaire items except where noted. We performed confirmatory factor 
analysis, reliability test and regression weight analysis. The scale items are described in the next section.

\section{Measurement}

\subsection{Works-Life Balance}

WLB was measured by Haar's (2013) three items scale. The scale items are: "I am satisfied with my work-life balance, enjoying both roles", "Nowadays, I seem to enjoy every part of my life equally well", and "I manage to balance the demands of my work and personal life well". The Cronbach's alpha is 0.75 .

\subsection{Job Satisfaction}

Job satisfaction was measured by the 4-items measure of Judge, Bono, Erez, and Locke (2005). The scale items are: "Most days I am enthusiastic about my work", "I feel fairly satisfied with my present job", "I find real enjoyment in my work", and the reversed item "I consider my job rather unpleasant". The Cronbach's alpha is 0.73 .

\subsection{Life Satisfaction}

Life satisfaction was measured by the 4-items scale of Diener, Emmons, Larsen, and Griffin (1985). The scale items are "In most ways my life is close to ideal", "The conditions of my life are excellent", "So far I have gotten the important things I want in life", "If I could live my life over, I would change almost nothing". The Cronbach's alpha is 0.80 .

\subsection{Job Autonomy}

Job Autonomy is a multi-item measure built in prior research (e.g. Martin \& Roman, 1996; Knudsen et al., 2003). Four items were asked about the respondent's perception of whether he/she can decide on his/her job. The items are: "I have a lot of say over what happens on my job", "I take part in job decisions that affect me", "I can decide how I do my work", and "I make a lot of decisions on my own". The items are rated on a 5-point scale (1- never to 5 -all the time). The Cronbach's alpha is 0.61 .

\subsection{Work Demands}

We used three items to measure work-demands. These three items are based on work role pressures from Yang et al. (2000). The items are: "I often feel that I am being run ragged 
from work", "I am given too much work to do" and "I have more work to do than I can do well". The Cronbach's alpha is 0.68 .

\subsection{Supervisor Work-Family Support}

Perceived supervisor support was assessed with five items from Eisenberger et al.'s (1986). These items ask about aid provided by the supervisor. These 5 items are: "My supervisor is helpful to me when I have a family or personal emergency", "My supervisor feels each of us is important as an individual", "My supervisor is helpful when I have a routine family or personal matter to attend to", "My supervisor is concerned about how employees think and feel about things" and "My supervisor is understanding when I have personal or family problems which interfere with my work". The Cronbach's alpha is 0.83 .

\subsection{Control variables}

In this study we introduced Age (years), Gender (coded as $1=$ female, $0=$ male) and Sector (coded as $1=$ public and $0=$ private) as control variables. Age, Gender, and Sector were chosen because of these control variables may influence the dependent variables. It is likely that age could influence WLB if experience gained through years might help to manage individual's life roles. Regarding gender, traditional roles between men and women are still dominant in Iranian culture nowadays. As a consequence, it is likely that work and family demands have higher effects on women (Beigi et al. 2012). Figure 2 shows the structural model including the items associated to each factor as well as the control variables.

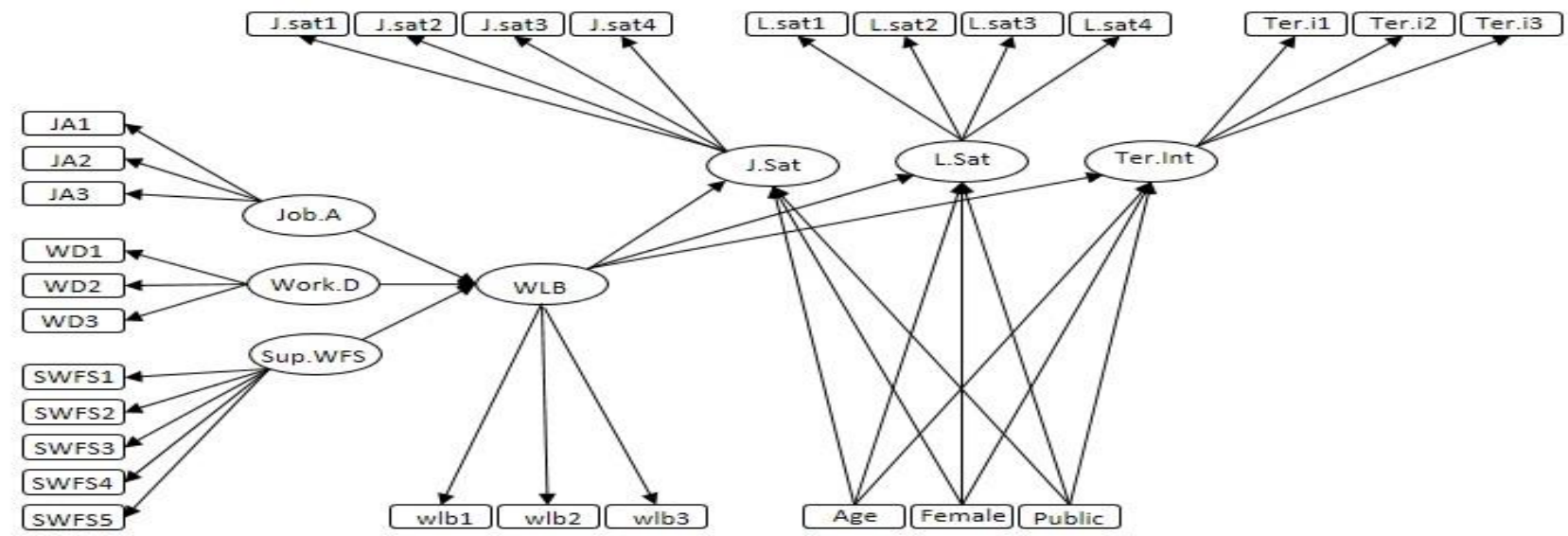

Figure 2: Structural model including factors, observed variables and control variables 


\subsection{Measurement Model}

Means and standard deviations of the observed variables are listed on Table 1. We performed CFA in AMOS.

Table 1: Means and Standard deviation of questionnaire items

\begin{tabular}{|c|c|c|c|c|c|}
\hline Item & Mean & Std. dev. & Item & Mean & Std. dev. \\
\hline wlb1 & 3,103 & ,070 & ter.i1 & 3,867 & ,267 \\
\hline wlb2 & 2,934 & ,071 & ter.i2 & 4,086 & ,289 \\
\hline wlb3 & 3,368 & ,079 & ter.i3 & 4,147 & ,244 \\
\hline WD1 & 2,904 & ,088 & L.sat1 & 2,875 & ,282 \\
\hline WD2 & 3,096 &, 079 & L.sat2 & 2,680 &, 272 \\
\hline WD3 & 2,625 &, 078 & L.sat3 & 2,891 & ,237 \\
\hline JA1 & 3,044 &, 083 & L.sat4 & 2,073 &, 112 \\
\hline JA2 & 3,824 & ,059 & J.sat1 & 2,824 &, 180 \\
\hline JA3 & 3,397 & ,069 & J.sat2 & 2,465 & 211 \\
\hline SWFS1 & 3,426 &, 074 & J.sat3 & 2,370 &, 175 \\
\hline SWFS2 & 3,500 & ,069 & J.sat4 & 3,139 &, 158 \\
\hline SWFS3 & 3,279 & ,080 & & & \\
\hline SWFS4 & 3,221 &, 069 & & & \\
\hline SWFS5 & 2,676 & ,086 & & & \\
\hline
\end{tabular}

Table 2 shows the correlations matrix between the studied factors. The measurement model included all the described factors: WLB, life satisfaction, job satisfaction, job autonomy, turnover intention, work demand, supervisor work-family support. Totally, the model fit the data well according to Williams, Vandenberg, and Edwards' (2009) recommendations. In our model Chi-square is 703,893 , and degrees of freedom is 332 , and $p$-value is $p<0.000$. In the study model RMSEA is 0,091 which is good enough to confirm that our sample is invariant metric and could be used in the analysis of a complex model (Williams et al., 2009).

Table 2: Correlation matrix of studied factors

\begin{tabular}{|l|c|c|c|c|c|c|c|c|c|}
\hline & $\begin{array}{c}\text { Work } \\
\text { Dem. }\end{array}$ & $\begin{array}{c}\text { Sup. } \\
\text { WFS }\end{array}$ & $\begin{array}{c}\text { Job } \\
\text { Aut. }\end{array}$ & WLB & $\begin{array}{c}\text { Turn. } \\
\text { Int. }\end{array}$ & $\begin{array}{c}\text { Life } \\
\text { Sat. }\end{array}$ & $\begin{array}{c}\text { Job } \\
\text { Sat. }\end{array}$ & Age & Gend. \\
\hline Sup. WFS & $-0,281$ & & & & & & & & \\
\hline Job Aut. & $-0,196$ & 0,060 & & & & & & & \\
\hline WLB & $-0,597$ & 0,361 & 0,258 & & & & & & \\
\hline Turn. Int. & 0,447 & $-0,457$ & $-0,123$ & $-0,282$ & & & & & \\
\hline Life Sat. & $-0,084$ & 0,218 & 0,261 & 0,536 & $-0,170$ & & & & \\
\hline
\end{tabular}




\begin{tabular}{|l|c|c|c|c|c|c|c|c|c|}
\hline Job Sat. & $-0,697$ & 0,561 & 0,254 & 0,644 & $-0,760$ & 0,467 & & & \\
\hline Age & $-0,306$ & 0,058 & 0,010 & 0,102 & $-0,429$ & 0,015 & 0,382 & & \\
\hline Gender & 0,236 & 0,142 & 0,037 & $-0,082$ & $-0,071$ & 0,121 & $-0,093$ & $-0,284$ & \\
\hline Sector & $-0,273$ & $-0,159$ & $-0,112$ & $-0,013$ & $-0,132$ & $-0,284$ & 0,070 & 0,219 & $-0,398$ \\
\hline
\end{tabular}

\section{Results}

We tested the hypotheses using SEM in AMOS (Hypotheses 1-6). We obtained CMIN/DF: 2.120 which is a suitable value, as Carmines \& McIver (1981) stated CMIN/DF would be acceptable and would show good fit between model and data if it is between the range of 2 to 1 or 3 to 1 . Another model fit indicator CFI: 0,747 shows an acceptable fit between our model and data; and finally, RMSEA: 0,091 also indicates a moderate fit. In other words, there is a suitable fit between the model and the data (Williams et al., 2009; Hair et al., 2010).

Table 3 shows the results of path analysis using SEM to test our hypotheses. Table 3 shows that the relationship between WLB and job satisfaction is significant ( $p$-value $\leq 0.001$ and estimate is 1.266). WLB is positively related to job satisfaction. This finding supports hypothesis $\mathrm{H} 1$ at $99.9 \%$ reliability. We are able to confirm hypothesis $\mathrm{H} 2$ with $99.9 \%$ reliability as well, since the relationship between WLB and life satisfaction is significant and reliable ( $p$-value $\leq$ 0.001). Results in table 3 support hypothesis $\mathrm{H} 3$ which indicates the relationship between WLB and turnover intention is negative and strong (estimate= -1.032). The p-value shows high reliability at confirming H3 ( -value $\leq 0.001$ ). Regarding to the relationship between WLB and its antecedents we find that job autonomy has a positive and strong relationship towards WLB (estimate $=1.062)$. This is reliable at more than 95\% reliability level ( $p$-value $=0.043$ ); hence, job autonomy is positively related to WLB and we are able to confirm hypothesis H4. Results on table 3 also confirm hypothesis H5 which reveal that the relationship between work demands and WLB is reliable and negative (estimate $=-0.398$ ). Higher work demands decrease WLB. P-value shows this relationship is reliable at more than $99.9 \%$ (p-value <0.001). Finally, the relationship between supervisor work-family support and WLB is significant and positive. Table 3 shows high reliability at more than $99.9 \%$ (estimate $=0.343$ ). Thus, we are able to confirm hypothesis H6 stating that higher supervisor support increases WLB. Regarding the control variables, we found that there are no significant relationships between gender and job satisfaction, and life 
satisfaction. However, we found a significant relationship of gender towards turnover intentions (estimate $=-0.422, \mathrm{p}$-value $=0.004)$, which indicates that female employees have lower turnover intentions than male employees. Regarding other control variables, Table 3 shows that age has a positive relationship towards job satisfaction (estimate $=0.017$; -value $\leq 0.001$ ), and a negative relationship towards turnover intentions (estimate $=-0.035 ; \mathrm{p}$-value $\leq 0.001$ ) showing that elder employees are more satisfied with their jobs and have less intentions to leave the company than the younger employees. We cannot confirm the relationship between age and life satisfaction. Findings on Table 3 also show a significant relationship between sector and life satisfaction showing that public employees are less satisfied with their lives (estimate $=-0.137$, p-value $=$ 0.034). We could not confirm the influence between the sector and the other outcomes variables.

\section{Discussion}

This study inquired about the antecedents and outcomes of WLB in Iran. Particularly, we investigated whether Job Autonomy, Work Demands, and Supervisor Work-Family Support impact WLB, which, in turn may impact job satisfaction, life satisfaction and turnover intentions of Iranian employees. We found consistent support for WLB antecedents and outcomes in Iran as showed on Figure 3. We found strong support for the hypothesized relationships between WLB and job satisfaction, life satisfaction and turnover intentions, in the expected directions. This study extends the previous research on Work-Life Balance that has been mostly done in developed countries (Karimi, 2006). It is important to note that the studied country still has significant differences from western countries including its system about gender roles. Thus, our paper tried to understand the functioning of WLB with regards to values and opinions of Iranian employees. In Iran, the number female employees have increased and traditional family roles where the man was the only breadwinner started to be replaced by dual-career families (Karimi, 2009).

Table 3: Structural model path analysis results

\begin{tabular}{|l|c|c|c|c|}
\hline & Estimates & S.E & C.R & P Label \\
\hline WLB <--- Job.A & 1.062 &, 525 & 2.024 & .043 \\
\hline WLB <--- Work.D &,- 398 &, 105 & $-3,779$ & $* * *$ \\
\hline WLB <--- Sup.WFS &, 343 &, 087 & 3,926 & $* * *$ \\
\hline J.Sat <--- WLB & 1,266 &, 227 & 5,572 & $* * *$ \\
\hline
\end{tabular}




\begin{tabular}{|l|c|c|c|c|}
\hline L.Sat <--- WLB &, 854 &, 206 & 4,136 & $* * *$ \\
\hline Ter.Int <--- WLB & $-1,032$ &, 210 & $-4,923$ & $* * *$ \\
\hline J.Sat<--- Age &, 017 &, 004 & 4,118 & $* * *$ \\
\hline L.Sat <--- Age &, 000 &, 007 &,- 008 &, 994 \\
\hline Ter.Int <--- Age &,- 035 &, 006 & $-5,480$ & $* * *$ \\
\hline J.Sat <--- Sector &, 012 &, 038 &, 311 &, 755 \\
\hline L.Sat <--- Sector &,- 137 &, 065 & $-2,117$ &, 034 \\
\hline Ter.Int <--- Sector &, 056 &, 058 &,- 969 &, 332 \\
\hline J.Sat <--- Gender &, 006 &, 094 &, 059 &, 953 \\
\hline L.Sat <--- Gender &, 183 &, 160 & 1,149 &, 251 \\
\hline Ter.Int <--- Gender &,- 422 &, 145 & $-2,915$ &, 004 \\
\hline
\end{tabular}

Karimi (2008) mainly focused on work-family conflict in Iran. She considered some antecedents such as gender, marital status, age, and working hours. We strived to get a broader perspective and we analyzed work-life balance, as well as its relationships with contextual factors, so we included job autonomy, work demand, and supervisor work-family support as antecedents of WLB while, at the same time, we studied job satisfaction, life satisfaction and turnover intentions as outcomes of WLB. In addition, we introduced control variables such as age, gender, and sector. The current study has remarkable contributions to the previous studies about work-life interaction. This research shows that WLB as a concept is different from workfamily conflict and work-family enrichment (Valcour, 2007). WLB reveals different views of thinking about the intersection between job and life. In the current study, employees have been selected from a wide variety of economic activities, such as higher education, public institutions, and private companies. We found strong support for WLB to be related with all the studied outcomes. We found that WLB increases job and life satisfaction and decreases turnover intentions in Iran. These results suggest that people who feel balanced tend to stay on the job (Casper \& Harris, 2008) and are more satisfied with their jobs and lives. The results of this research align with previous studies which describe outcomes of WLB developed in Western countries (Allen, 2001; Brough \& O’Driscoll, 2005; Brough et al. 2014). Regarding the antecedents of WLB, we found that there is a significant relationship between supervisor workfamily support and WLB. Having a supportive supervisor increases individuals' WLB. Our results also suggest that lower work demands are associated to higher levels of WLB. Regarding 
job autonomy we found a beneficial effect of job autonomy on WLB. This suggests that employees enjoying higher job autonomy and having supportive supervisors are more balanced and experience a higher sense of harmony between their work and personal life. This is the first study, to our knowledge, that evaluates the antecedents and outcomes of WLB in Iran. These results may hold true in other Middle East countries.

\section{Antecedents $\quad$ Outcomes}

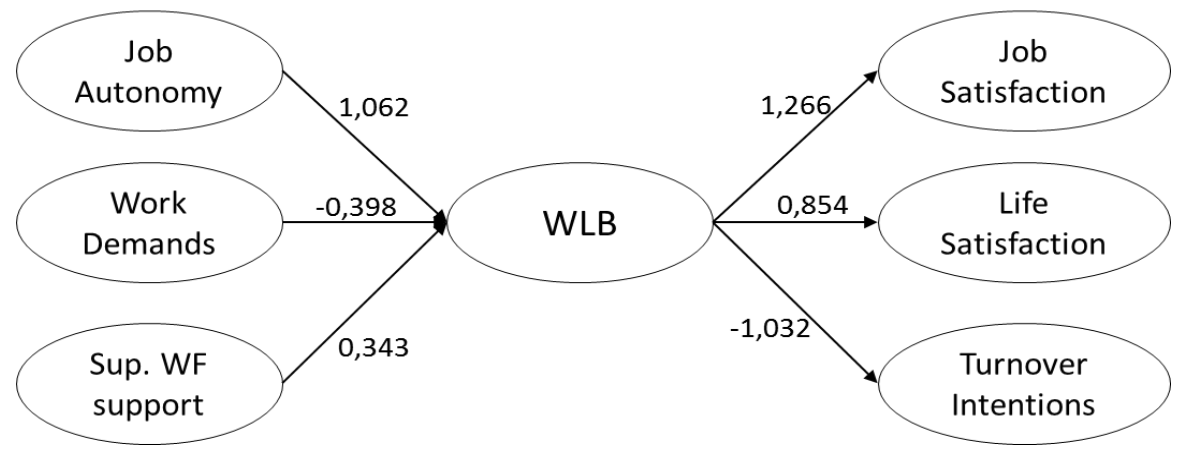

Figure 3: Path Analysis Results of Studied Factors in SEM

\section{Conclusion and Future Research}

This research extends our understandings on WLB by showing the relationships between its antecedents and outcomes. This study develops previous work on WLB especially in an understudied country (Beigi et al. 2012). We believe that this study will be helpful for future research on WLB as there are still few studies on the relationship between antecedents and outcomes of WLB in Iran. It is important to compare the results from Iran with Western countries such as European or American countries, so we believe this might be a future avenue of research. In addition, we claim for further research on the work-life interface in other Middle East countries. More research is needed to better understand WLB in the Middle-East cultures. 


\section{REFERENCES}

Ahuja, M. K., Chudoba, K. M., Kacmar, C. J., McKnight, D. H., \& George, J. F. (2007). IT road warriors: Balancing work-family conflict, job autonomy, and work overload to mitigate turnover intentions. Mis Quarterly, 31(1), 1-17. https://doi.org/10.2307/25148778

Allen, T. D., Herst, D. E.., Bruck, C. S., \& Sutton, M. (2000). Consequences associated with work-to-family conflict: A review and agenda for future research. Journal of Occupational Health Psychology, 5(2), 278-308. https://doi.org/10.1037/1076$\underline{8998.5 .2 .278}$

Allen, T. D. (2001). Family-supportive work environments: The role of organizational perceptions. Journal of Vocational Behavior, 58(3), 414-435. https://doi.org/10.1006/jvbe.2000.1774

Beauregard, T. A., \& Henry, L. C. (2009). Making the link between work-life balance practices and organizational performance. Human resource management review, 19(1), 9-22. https://doi.org/10.1016/j.hrmr.2008.09.001

Beigi, M., Ershadi, S. M., \& Shirmohammadi, M. (2012). Work-family conflict and its antecedents among Iranian operating room personnel. Management Research Review, 35(10), 958-973. https://doi.org/10.1108/01409171211272688

Bond, J. T., Galinsky, E., \& Swansberg, J. E. (1997). The National Study of the Changing Work-force, 1997. No. 2. New York: Families and Work Institute.

Boyar, S.L., Maertz, C.P., Pearson, A.W., \& Keough, S. (2003). Work-Family Conflict: A Model of Linkages Between Work And Family Domain Variables And Turnover Intentions, Journal of Managerial Issues, 15(2), 175-190.

Brough, P., Timms, C., O'Driscoll, M. P., Kalliath, T., Siu, O. L., Sit, C., \& Lo, D. (2014). Work-life balance: a longitudinal evaluation of a new measure across Australia and New Zealand workers. The International Journal of Human Resource Management, 25(19), 2724-2744. https://doi.org/10.1080/09585192.2014.899262

Brough, P., O’Driscoll, M., \& Kalliath, T. (2007). Work-Family Conflict and Facilitation: Achieving work-family balance, in I. Glendon, B. Myors, \& B. Thompson (Eds.), 
Advances in Organizational Psychology: An Asia Pacific Perspective (pp. 73-92). Sydney: Australian Academic Press.

Brough, P., \& O'Driscoll, M. (2005). Work-family conflict and stress. In S. G. Antoniou, \& C. L. Cooper (Eds.). Research companion to organizational health psychology (pp. 346365). Cheltenham UK: Edward Elgar. https://doi.org/10.4337/9781845423308.00032

Burke, R. J. (2002). Work stress and women's health: Occupational status effects. Journal of Business Ethics, 37(1), 91-102. https://doi.org/10.1023/A:1014734302972

Byron, K. (2005). A meta-analytic review of work-family conflict and its antecedents. Journal of vocational behavior, 67(2), 169-198. https://doi.org/10.1016/j.jvb.2004.08.009

Carmines, E. G., \& McIver, J. P. (1981). Analyzing models with unobserved variables: Analysis of covariance structures. In G. Bohrnstedt, \& E. Borgatta (Eds.), Social measurement: Current issues (pp. 65-115). Beverly Hills, CA: Sage.

Casper, W. J., \& Harris, C. M. (2008). Work-life benefits and organizational attachment: Selfinterest utility and signaling theory models. Journal of Vocational Behavior, 72(1), 95109. https://doi.org/10.1016/j.jvb.2007.10.015

Clark, S. C. (2000). Work/family border theory: A new theory of work/family balance. Human relations, 53(6), 747-770. https://doi.org/10.1177/0018726700536001

Diener, E. D., Emmons, R. A., Larsen, R. J., \& Griffin, S. (1985). The satisfaction with life scale. Journal of Personality Assessment, 49(1), 71-75. https://doi.org/10.1207/s15327752jpa4901_13

Eisenberger, R., Huntington, R. Hutchinson, S., \& Sowa, D. (1986). Perceived Organizational Support. Journal of Applied Psychology, 71(3),500-507. https://doi.org/10.1037/0021$\underline{9010.71 .3 .500}$

Ferguson, M., Carlson, D., Zivnuska, S., \& Whitten, D. (2012). Support at work and home: The path to satisfaction through balance. Journal of Vocational Behavior, 80(2), 299-307. https://doi.org/10.1016/j.jvb.2012.01.001

Fu, C. K., \& Shaffer, M. A. (2001). The tug of work and family: Direct and indirect domainspecific determinants of work-family conflict. Personnel Review, 30(5), 502-522. https://doi.org/10.1108/EUM0000000005936 
Greenhaus, J., \& Allen, T. (2011). Work-family balance: A review and extension of the literature. In J. C. Quick, \& L. E. Tetrick (Eds.), Handbook of occupational health psychology. Washington, DC: American Psychological Association.

Greenhaus, J. H., Collins, K. M., \& Shaw, J. D. (2003). The relation between work-family balance and quality of life. Journal of Vocational Behavior, 63(3), 510-531. ttps://doi.org/10.1016/S0001-8791(02)00042-8

Greenhaus, J. H., \& Powell, G. N. (2003), When Work and Family Collide: Deciding Between Competing Role Demands. Organizational Behaviour and Human Decision Processes, 90(2), 291-303. https://doi.org/10.1016/S0749-5978(02)00519-8

Guest, D. E. (2002). Perspectives on the study of work-life balance. Social Science Information, 41(2), 255-279. https://doi.org/10.1177/0539018402041002005

Haar, J. M., Russo, M., Sune, A., \& Ollier-Malaterre, A. (2014). Outcomes of work-life balance on job satisfaction, life satisfaction and mental health: A study across seven cultures. Journal of Vocational Behavior, 85(3), 361-373. https://doi.org/10.1016/j.jvb.2014.08.010

Haar, J. M. (2013). Testing a new measure of WLB: A study of parent and non-parent employees from New Zealand. The International Journal of Human Resource Management, 24(17), 3305-3324. https://doi.org/10.1080/09585192.2013.775175

Hackman, J. R., \& Oldham, G. R. (1975). Development of the job diagnostic survey. Journal of Applied Psychology, 60(2), 159-70. https://doi.org/10.1037/h0076546

Hair, J. F., Anderson, R. E., Babin, B. J., \& Black, W. C. (2010). Multivariate data analysis: A global perspective (Vol. 7). Upper Saddle River, NJ: Pearson.

Judge, T. A., Bono, J. E., Erez, A., \& Locke, E. A. (2005). Core self-evaluations and job and life satisfaction: The role of self-concordance and goal attainment. Journal of Applied Psychology, 90(2), 257-268. https://doi.org/10.1037/0021-9010.90.2.257

Kaldenberg, D. O., \& Becker, B. W. (1992). Workload and psychological strain: A test of the French, Rodgers, and Cobb hypothesis. Journal of Organizational Behavior, 13(6), 617624. https://doi.org/10.1002/job.4030130607 
Kalliath, T., \& Brough, P. (2008), Work-Life Balance: A Review of the Meaning of the Balance Construct, Journal of Management and Organization, 14(3), 323-327.

Karimi, L. (2009). Do female and male employees in Iran experience similar work-family interference, job, and life satisfaction?. Journal of Family Issues, 30(1), 124-142. https://doi.org/10.1177/0192513X08324973

Karimi, L. (2006). A test of a model of work-family interface: A study of Iranian employees. Curtin, University of Technology Press.

Karimi, L. (2008). A study of a multidimensional model of work-family conflict among Iranian employees. Community, Work \& Family, 11(3), 283-295.

Karimi, L., \& Nouri, A. (2009). Do work demands and resources predict work-to-family conflict and facilitation? A study of Iranian male employees. Journal of Family and Economic Issues, 30(2), 193-202. https://doi.org/10.1007/s10834-009-9143-1

Kirchmeyer, C. (2000). Work-Life Initiatives: Greed or Benevolence Regarding Workers' Time?. Trends in organizational behavior, 7, 79-94.

Knudsen, H. K., Aaron Johnson, J., Martin, J. K., \& Roman, P. M. (2003). Downsizing survival: The experience of work and organizational commitment. Sociological Inquiry, 73(2), 265-283. https://doi.org/10.1111/1475-682X.00056

Kofodimos, J. R. (1993). Balancing act. San Francisco: Jossey-Bass.

Kossek, E. E., Valcour, M., \& Lirio, P. (2014). The sustainable workforce: Organizational strategies for promoting work-life balance and well-being. In C. Cooper, \& P. Chen (Eds.), Work and wellbeing (pp. 295-318). Oxford, UK: Wiley-Blackwell. https://doi.org/10.1002/9781118539415.wbwell030

Lagerström, M., Josephson, M., Arsalani, N., \& Fallahi-Khoshknab, M. (2010). Striving for balance between family and work demands among Iranian nurses. Nursing Science Quarterly, 23(2), 166-172. https://doi.org/10.1177/0894318410362543

Lobel, S. A., \& Kossek, E. E. (1996). Human resource strategies to support diversity in work and personal lifestyles: Beyond the "family friendly" organization. In E. E. Kossek \& S. A. Lobel (Eds.), Managing diversity: Human resource strategies for transforming the workplace (pp. 221-243). Cambridge, MA: Blackwell. 
Marks, S. R., \& MacDermid, S. M. (1996). Multiple roles and the self: A theory of role balance. Journal of Marriage and the Family, 58(2), 417-432. https://doi.org/10.2307/353506

Martin, J. K., \& Roman, P. M. (1996). Job Satisfaction, Job Rewards Characteristics, and Employees' Problem Drinking Behavior. Work and Occupations, 23(1), 4-25. https://doi.org/10.1177/0730888496023001002

Moorman, R. H., \& Podsakoff, P. M. (1992). A metaanalytic review and empirical test of the potential confounding effects of social desirability response sets in organizational behaviour research. Journal of Occupational and Organizational Psychology, 65(2), 131-149. https://doi.org/10.1111/j.2044-8325.1992.tb00490.x

Nishaat, B. Z. (2017). Achieving work family balance (WFB) among professional working women in Mauritius: A qualitative study. PEOPLE: International Journal of Social Sciences, 3(2), 2053-5074.

Noor, S., \& Maad, N. (2009). Examining the relationship between work life conflict, stress and turnover intentions among marketing executives in Pakistan. International journal of Business and Management, 3(11), 93. https://doi.org/10.5539/ijbm.v3n11p93

OECD, Organisation for Economic Co-operation and Development,. (2017, April 26). Retrieved from http://www.oecdbetterlifeindex.org/topics/work-life-balance/

O’Driscoll, M., Brough, P., \& Biggs, A. (2007). Work-Family Balance: Concepts, Implications and Interventions. In J. Houdmont \& S. McIntyre (Eds.). Occupational Health Psychology: European Perspectives on Research, Education and Practice (pp. 193-217). Nottingham: Nottingham University.

O’Shea, M. (2003). Culture Shock! Iran. Portland, OR: Graphic Arts Center Publishing.

Schwab, K. (2016). The Global Competitiveness Report 2016-2017. World Economic Forum. Retrieved from https://www.weforum.org/reports/the-global-competitiveness-report2016-2017-1

Soon, A., Quazi, H. A., Tay, C., \& Kelly, K. (2005). Studies on the Impact of Work-Life Initiatives on Employee \& Firm Performance. Executive Report for Public release. 
Steiber, N. (2009). Reported levels of time-based and strain-based conflict between work and family roles in Europe: A multilevel approach. Social Indicators Research, 93(3), 469488. https://doi.org/10.1007/s11205-008-9436-Z

Sultan, S., Kanwal, F., \& Gul, S. (2017). Giving versus receiving social support: An analysis of what contributes the most to favorable life outcomes. PEOPLE: International Journal of Social Sciences, 3(2), 762-774. https://doi.org/10.20319/pijss.2017.32.762774

Thomas, L. T. \& Ganster, D. C. (1995). Impact of family-supportive work variables on work-family conflict and strain: A control perspective, Journal of Applied Psychology, 80(1), 6-15. https://doi.org/10.1037/0021-9010.80.1.6

Thompson, C. A., Beauvais, L. L., \& Lyness, K. S. (1999). When work-family benefits are not enough: The influence of work-family culture on benefit utilization, organizational attachment, and work-family conflict. Journal of Vocational behavior, 54(3), 392-415. https://doi.org/10.1006/jvbe.1998.1681

Valcour, M. (2007). Work-based resources as moderators of the relationship between work hours and satisfaction with work-family balance. Journal of Applied Psychology, 92(6), 1512-1523. https://doi.org/10.1037/0021-9010.92.6.1512

Voydanoff, P. (1988). Work role characteristics, family structure demands, and work/family conflict. Journal of Marriage and the Family, 50(3), 749-761. https://doi.org/10.2307/352644

Wadsworth, L.L. and Owens, B.P. (2007), "The effects of social support on work-family enhancement and work-family conflict in the public sector", Public Administration Review, 67 (1), 75-87. https://doi.org/10.1111/j.1540-6210.2006.00698.x

Wang, P., Lawler, J.J., Shi, K., Walumbwa, F., \& Piao, M. (2008). Family-friendly employment practices: importance and effects in India, Kenya, and China. Advances in International Management, 21, 235-65. https://doi.org/10.1016/S1571-5027(08)00010-7

Williams, L. J., Vandenberg, R. J., \& Edwards, J. R. (2009). 12 structural equation modeling in management research: A guide for improved analysis. The Academy of Management Annals, 3(1), 543-604. https://doi.org/10.1080/19416520903065683 
Wise, S., \& Bond, S. (2003). Work-life policy: does it do exactly what it says on the tin?

Women in Management Review, 18(1/2), 20-31.

https://doi.org/10.1108/09649420310462307

Xie, J. L., and Johns, G. (1995). Job scope and stress: Can job scope be too high?. Academy of Management Journal, 38(5), 1288-1309. https://doi.org/10.2307/256858

Yang, N., Chen, C. C., Choi, J., \& Zou, Y. (2000). Sources of work-family conflict: A Sino-US comparison of the effects of work and family demands. Academy of Management Journal, 43(1), 113-123. https://doi.org/10.2307/1556390

Yildirim, D., \& Aycan, Z. (2008). Nurses' work demands and work-family conflict: A questionnaire survey. International journal of nursing studies, 45(9), 1366-1378. https://doi.org/10.1016/j.ijnurstu.2007.10.010 